\title{
Structural characterization and photoluminescence behavior of pure and doped potassium strontium niobates ceramics with tetragonal tungsten-bronze structure
}

\author{
A.R.F. Lima ${ }^{a}$, J.C. Sczancoski ${ }^{\mathrm{a}}$,, M. Siu Li ${ }^{\mathrm{c}}$, E. Longo ${ }^{\mathrm{b}}$, E.R. Camargo ${ }^{\mathrm{a}, *}$ \\ ${ }^{a}$ LIEC-Departamento de Química - UFSCar Universidade Federal de São Carlos, 13565-905 São Carlos, SP, Brazil \\ ${ }^{\mathrm{b}}$ Instituto de Química - UNESP Universidade Estadual Paulista, 14801-907 Araraquara, SP, Brazil \\ ${ }^{\mathrm{c}}$ IFSC-Universidade de São Paulo, 13560-970 São Carlos, SP, Brazil
}

Received 4 July 2015; received in revised form 18 November 2015; accepted 23 November 2015

Available online 7 December 2015

\begin{abstract}
$\mathrm{KSr}_{2} \mathrm{Nb}_{5} \mathrm{O}_{15}$ and $\mathrm{K}_{1.2} \mathrm{Sr}_{1.6} \mathrm{Ln}_{0.2} \mathrm{Nb}_{5} \mathrm{O}_{15}$ ( $\mathrm{Ln}=\mathrm{La}$, Pr, and $\mathrm{Nd}$ ) were synthesized by the Pechini method and calcined at $1373 \mathrm{~K}$ for $10 \mathrm{~h}$ under air atmosphere. Rietveld refinements indicated the presence of structural defects in both KSN and KSN- $2 n$, especially distortions in $\mathrm{O}-\mathrm{Nb}-\mathrm{O}$ and $\mathrm{Nb}-\mathrm{O}-\mathrm{Nb}$ bonds. Modifications in bond distances of $\left[\mathrm{NbO}_{6}\right]$ clusters were also confirmed by Raman spectroscopy. Ultraviolet-visible absorption spectra and photoluminescence profiles were influenced by lanthanide atoms in the band structure of modified KSN materials, creating new defects and intermediary energy levels within the band gap.
\end{abstract}

(c) 2015 Elsevier Ltd and Techna Group S.r.l. All rights reserved.

Keywords: C. Optical properties; Ceramics; Optical materials; X-ray diffraction; Crystal structure

\section{Introduction}

Over the last years, the scientific community demonstrated an enormous interest in new ceramic materials with superior physical and chemical properties [1]. In this context, potassium strontium niobate $\left(\mathrm{KSr}_{2} \mathrm{Nb}_{5} \mathrm{O}_{15}\right.$, hereafter referred to as $\left.\mathrm{KSN}\right)$ is a potential candidate for the next generation of storage and electro-optical devices [2,3]. This oxide exhibits a tetragonal tungsten bronze structure (TTB-type) [4], usually described by the chemical formula $\left(\mathrm{A}_{1}\right)_{2}\left(\mathrm{~A}_{2}\right)_{4} \mathrm{C}_{4} \mathrm{Nb}_{10} \mathrm{O}_{30}$, where $\mathrm{A}_{1}, \mathrm{~A}_{2}$, and $\mathrm{C}$ denote different sites for cations in the crystalline structure $[5,6]$.

$\mathrm{KSN}$ is an uniaxial ferroelectric material with a single polar axis along the [001] direction [7], exhibiting a spontaneous polarization of approximately $27.1 \mu \mathrm{C} \mathrm{m}^{-2}$ due to the displacement of $\mathrm{Nb}$ atoms from the center of $\left[\mathrm{NbO}_{6}\right]$ clusters [8].

\footnotetext{
*Correspondence to: LIEC-Department of Chemistry UFSCar-Federal Universisty of São Carlos, Rod. Washington Luis, km 235, CP 676, São Carlos 13565-905, SP, Brazil. Tel.: +55 163351 8090; fax: +55 1633518350.

E-mail address: camargo@ufscar.br (E.R. Camargo).
}

In terms of optical properties, Zhu et al. [9] and Ding et al. [10] reported the photoluminescence (PL) emissions of Eu-doped $\mathrm{NaSr}_{2} \mathrm{Nb}_{5} \mathrm{O}_{15}$ and Dy-doped $\mathrm{KBa}_{2} \mathrm{Nb}_{5} \mathrm{O}_{15}$ powders synthesized by the solid-state reaction. They observed in both systems the predominance of intense lines in the excitation spectra associated to charge transfer transitions of rare earth elements. The luminescence intensities were correlated with the charge compensation due to positive defects created when trivalent ions $\left(\mathrm{Eu}^{3+}\right.$ or $\left.\mathrm{Dy}^{3+}\right)$ substituted bivalent ions $\left(\mathrm{Sr}^{2+}\right.$ or $\mathrm{Ba}^{2+}$ ) into the host structure $[9,10]$.

Although several properties of KSN based materials are strongly dependent on the presence of doping elements, only few studies tried to explain the relation between the structural changes induced by different elements in the crystalline lattice of KSN and the PL spectra with respect to the local distortions. In this study, we investigate the structural and optical properties of pure and doped KSN powders synthesized by the Pechini method [11-13]. The crystalline structure of single phase samples were analyzed to identify the distortions in the crystalline lattice caused by the presence of small quantities of 
lanthanides, while ultraviolet-visible (UV-vis) absorption spectroscopy and photoluminescent (PL) measurements were performed to estimate the electronic characteristics of each sample, which were discussed in terms of structural distortions.

\section{Experimental}

Ammonium niobium oxalate $\mathrm{NH}_{4} \mathrm{H}_{2}\left[\mathrm{NbO}\left(\mathrm{C}_{2} \mathrm{O}_{4}\right)_{3}\right] \cdot x \mathrm{H}_{2} \mathrm{O}$ (CBMM-Brazil), lanthanum oxide $\mathrm{La}_{2} \mathrm{O}_{3}$ (>99.9\%, Aldrich), praseodymium acetate $\mathrm{Pr}\left(\mathrm{CH}_{3} \mathrm{CO}_{2}\right)_{3} \cdot 3 \mathrm{H}_{2} \mathrm{O}(\geq 99.9 \%$, NOAH Technologies Corporation), neodymium oxide $\mathrm{Nd}_{2} \mathrm{O}_{3}(\geq$ 99.9\%, Aldrich), strontium nitrate $\mathrm{Sr}\left(\mathrm{NO}_{3}\right)_{2}$ ( $\geq 99 \%$, Aldrich), potassium oxalate $\mathrm{K}_{2} \mathrm{C}_{2} \mathrm{O}_{4} \cdot \mathrm{H}_{2} \mathrm{O}$ ( $\geq 99.5 \%$, Aldrich), anhydrous citric acid (CA) ( $\geq 99.5 \%$, Aldrich) and ethylene glycol (EG) $\left(\geq 99.9 \%\right.$, J.T. Baker $\left.{ }^{\mathbb{R}}\right)$ were used as received. Initially, CA, EG and niobium oxalate were dissolved in deionized water at $393 \mathrm{~K}$ under constant stirring. Thereafter, stoichiometric amounts of the other salts were added in this solution to complete the desired stoichiometry. Small amounts of diluted nitric acid (P.A. Synth) were used in order to favor the dissolution of $\mathrm{La}_{2} \mathrm{O}_{3}$ and $\mathrm{Nd}_{2} \mathrm{O}_{3}$. The molar ratio of $\mathrm{CA} /$ metal cations was fixed at $4: 1$, while the mass ratio of $\mathrm{CA} / \mathrm{EG}$ was adjusted to 60:40. The solvent was evaporated from the solutions up to get a viscous resin, which was heat-treated at $623 \mathrm{~K}$ for $3 \mathrm{~h}$. The obtained precursor powders were calcined at $1373 \mathrm{~K}$ for $10 \mathrm{~h}$ under air atmosphere. The crystalline powders were analyzed by XRD (Shimadzu XRD-6000, $\mathrm{Cu} K \alpha$ radiation, scanning step of $0.02^{\circ}$, counting time of $6 \mathrm{~s}$ and $2 \theta$ range from $5^{\circ}$ to $120^{\circ}$ ), micro-Raman spectroscopy (Horiba Jobin YvonHR550 Spectrometer, equipped with an argon ion laser, $\lambda=514.5 \mathrm{~nm}$ ), The samples were also characterized by UVvis absorption spectroscopy (Cary 5G spectrophotometer in diffuse reflection mode) and PL measurements (Coherent Innova 90-K krypton ion laser system, $\lambda=350 \mathrm{~nm}$, incident laser beam power maintained at $50 \mathrm{~mW}$ ).

\section{Results and discussion}

XRD patterns of pure KSN and doped $\mathrm{K}_{1.2} \mathrm{Sr}_{1.6} L n_{0.2} \mathrm{Nb}_{5} \mathrm{O}_{15}$ $(\mathrm{KSN}-\mathrm{Ln}$, with $L n=\mathrm{La}, \mathrm{Pr}$, or $\mathrm{Nd})$ shown in Fig. 1 were perfectly indexed with the TTB-type structure (PDF 01-0747178) without any evidence of secondary phases. Exploratory trials to synthesize doped KSN without excess of potassium resulted in secondary phases, while samples with $20 \%$ of potassium in excess resulted in single phase. Although lanthanides ions usually exhibit the same oxidation state (+ III), their electronic configurations present different number of $4 \mathrm{f}$ electrons, which can affect the electronic properties of the host solid in different ways without affecting the electro neutrality or the presence of structural defects. For instance, $\mathrm{La}^{3+}$ does not have any f electron, while $\mathrm{Pr}^{3+}$ and $\mathrm{Nd}^{3+}$ have 2 and 3 unpaired f electrons, respectively. All samples were refined by the Rietveld method using the GSAS program [14]. The input data of the theoretical model were those available in the ICSD database (Code 95741) [15]. The refinement results,

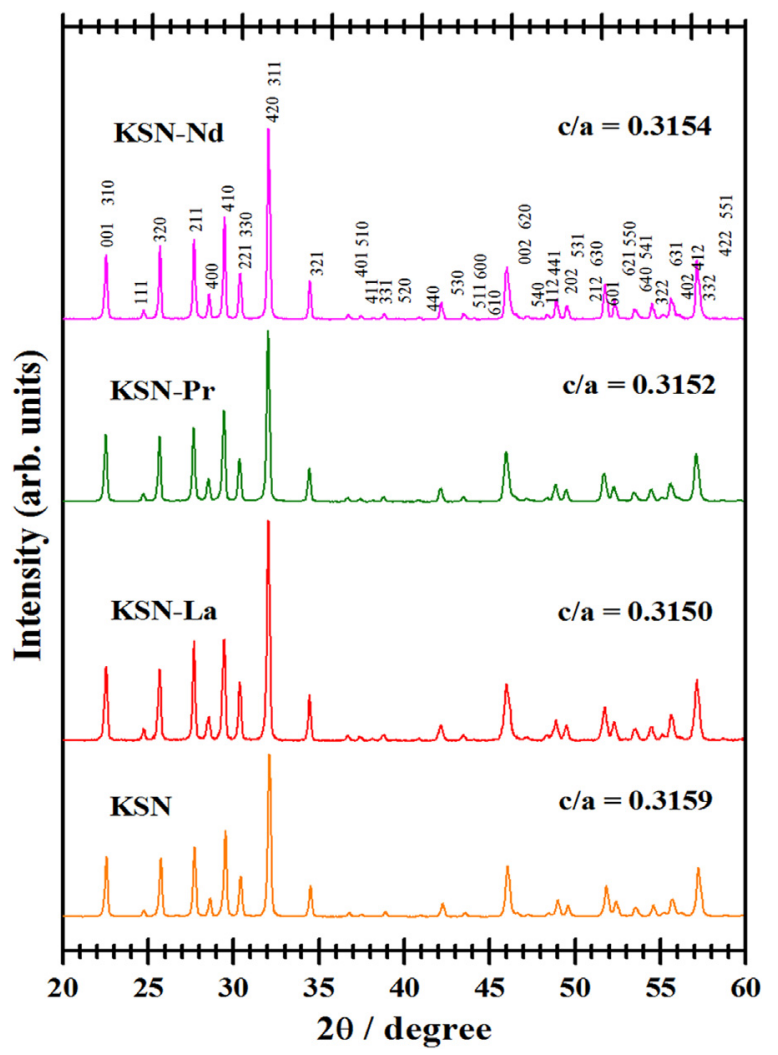

Fig. 1. XRD patterns of $\mathrm{KSN}$ and $\mathrm{KSN}-\operatorname{Ln}(\operatorname{Ln}=\mathrm{La}, \mathrm{Pr}$, and $\mathrm{Nd})$ calcined at $1373 \mathrm{~K}$ for $10 \mathrm{~h}$.

summarized in Supplementary Data, confirm the incorporation of distinct lanthanide atoms into the KSN host lattice in the icosahedron site previously occupied by the strontium cation. Although the good correlation between observed and calculated XRD patterns (Table S5-Supplementary Data), slight variations of the lattice parameters, unit cell volume and $c / a$ ratio were detected in the samples modified with different rare earths. Strontium exhibits larger ionic radii than lanthanides ions introduced in the composition, which obviously affects the lattice parameters of the host structure, but the distortions induced in angles and bonds of niobium octahedral should also modify the lattice parameters.

Fig. 2 illustrates the KSN structure using the lattice parameters and atomic positions taken from the Rietveld refinements [16]. In this structure, strontium atoms bond to twelve oxygen atoms $\left[\mathrm{SrO}_{12}\right]$ and the potassium to fifteen oxygens $\left[\mathrm{KO}_{15}\right]$ (not shown). The key information is the offcenter position of $\mathrm{Nb}$ atoms inside the octahedral $\left[\mathrm{NbO}_{6}\right]$ clusters, which affects the $\mathrm{O}-\mathrm{Nb}-\mathrm{O}$ bond angles. According to Fig. 2, there are distorted $\left[\mathrm{NbO}_{6}\right]$ clusters with three different $\mathrm{O}-\mathrm{Nb}-\mathrm{O}$ bond angles (Table 1). There are also distortions in $\mathrm{Nb}-\mathrm{O}-\mathrm{Nb}$ bonds that connect the $\left[\mathrm{NbO}_{6}\right]$ clusters. These results suggest the occurrence of significant changes that modify the crystalline lattice of KSN due the incorporation of lanthanide atoms.

The bands at $600 \mathrm{~cm}^{-1}$ and $650 \mathrm{~cm}^{-1}$ in Raman spectra of Fig. 3 are assigned to $\mathrm{Nb}-\mathrm{O}$ symmetric stretching modes of octahedral $\left[\mathrm{NbO}_{6}\right]$ clusters and the band located at $240 \mathrm{~cm}^{-1}$ 


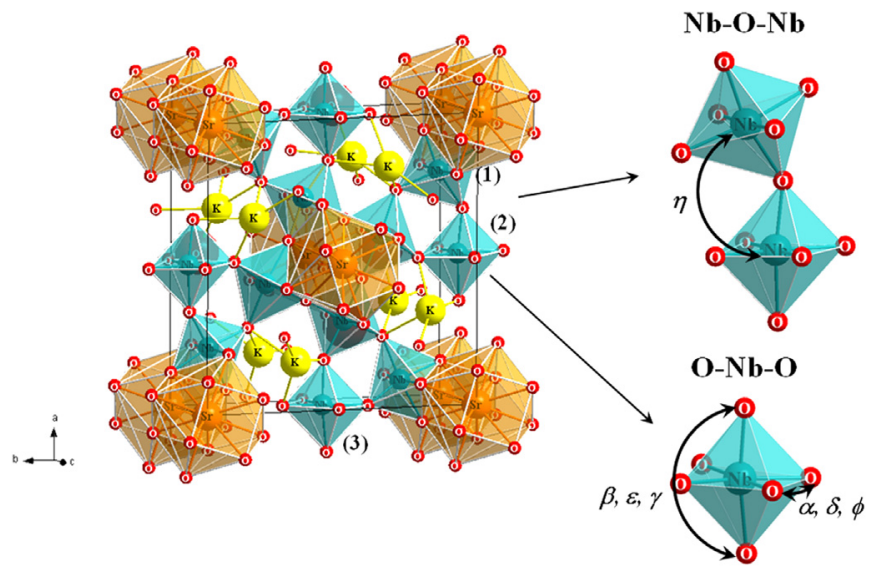

Fig. 2. Schematic representation of $\mathrm{KSN}$ structure, illustrating the $\left[\mathrm{SrO}_{12}\right]$, $\left[\mathrm{NbO}_{6}\right]$ and $\left[\mathrm{NbO}_{6}\right]-\left[\mathrm{NbO}_{6}\right]$ clusters.

Table 1

Bond angles estimated for $\left[\mathrm{NbO}_{6}\right]$ clusters $\left(\mathrm{O}-\mathrm{Nb}-\mathrm{O}\right.$ bonds) and $\left[\mathrm{NbO}_{6}\right]-$ $\left[\mathrm{NbO}_{6}\right]$ clusters $(\mathrm{Nb}-\mathrm{O}-\mathrm{Nb}$ bonds).

\begin{tabular}{|c|c|c|c|c|c|c|c|}
\hline \multirow[t]{2}{*}{ Sample } & \multicolumn{2}{|c|}{$\mathrm{O}-\mathrm{Nb}-\mathrm{O}(1)$} & \multicolumn{2}{|c|}{$\mathrm{O}-\mathrm{Nb}-\mathrm{O}(2)$} & \multicolumn{2}{|c|}{$\mathrm{O}-\mathrm{Nb}-\mathrm{O}(3)$} & \multirow{2}{*}{$\begin{array}{l}\mathrm{Nb}-\mathrm{O}-\mathrm{Nb} \\
\eta\end{array}$} \\
\hline & $\alpha$ & $\beta$ & $\delta$ & $\varepsilon$ & $\phi$ & $\gamma$ & \\
\hline $\mathrm{KSN}$ & 84.64 & 162.71 & 80.65 & 161.31 & 82.00 & 173.62 & 141.29 \\
\hline KSN-La & 83.97 & 165.21 & 89.60 & 179.20 & 79.53 & 165.46 & 146.64 \\
\hline KSN-Pr & 89.29 & 169.11 & 89.29 & 171.16 & 89.71 & 177.27 & 143.60 \\
\hline KSN-Nd & 90.58 & 169.82 & 85.51 & 171.03 & 88.41 & 170.92 & 146.15 \\
\hline KSN & 84.64 & 162.71 & 80.65 & 161.31 & 82.00 & 173.62 & 141.29 \\
\hline
\end{tabular}

is related to $\mathrm{Nb}-\mathrm{O}-\mathrm{Nb}$ bending modes due to the tilting of adjacent $\left[\mathrm{NbO}_{6}\right]$ clusters [17]. The broadening of these bands comes from the structural order-disorder caused by the modifications in $\mathrm{O}-\mathrm{Nb}-\mathrm{O}$ and $\mathrm{Nb}-\mathrm{O}-\mathrm{Nb}$ bonds $[18,19]$.

In general, the Raman spectroscopy is very sensitive to changes in the structure of oxides, especially in the region of metal-oxygen stretching modes [17]. It is evident a slight shift of the band at $600 \mathrm{~cm}^{-1}$ to lower wavelength depending on the lanthanide atom inserted into the KSN host lattice. For instance, this peak appears centered at $608.9 \mathrm{~cm}^{-1}$ in the spectrum of pure KSN, but it was shifted to $601.5 \mathrm{~cm}^{-1}$ when the structure was modified with praseodymium, a value obviously greater than the equipment resolution. Since the modified $\left[\mathrm{Ln} \mathrm{O}_{12}\right]$ clusters are connected to $\left[\mathrm{NbO}_{6}\right]$ clusters, it is plausible consider that the doping lanthanides effectively affect the structural organization of the lattice, mainly modifying the bond distances between the $\mathrm{Nb}-\mathrm{O}$ bonds of $\left[\mathrm{NbO}_{6}\right]$ clusters.

Lanthanide elements are usually employed as probe to understand the band structure as well as the crystalline organization of semiconductor materials through their PL and UV-vis absorption spectra [20]. In principle, doping atoms or structural defects, such as distortions in chemical bonds, dislocations or oxygen vacancies, modify the band structure

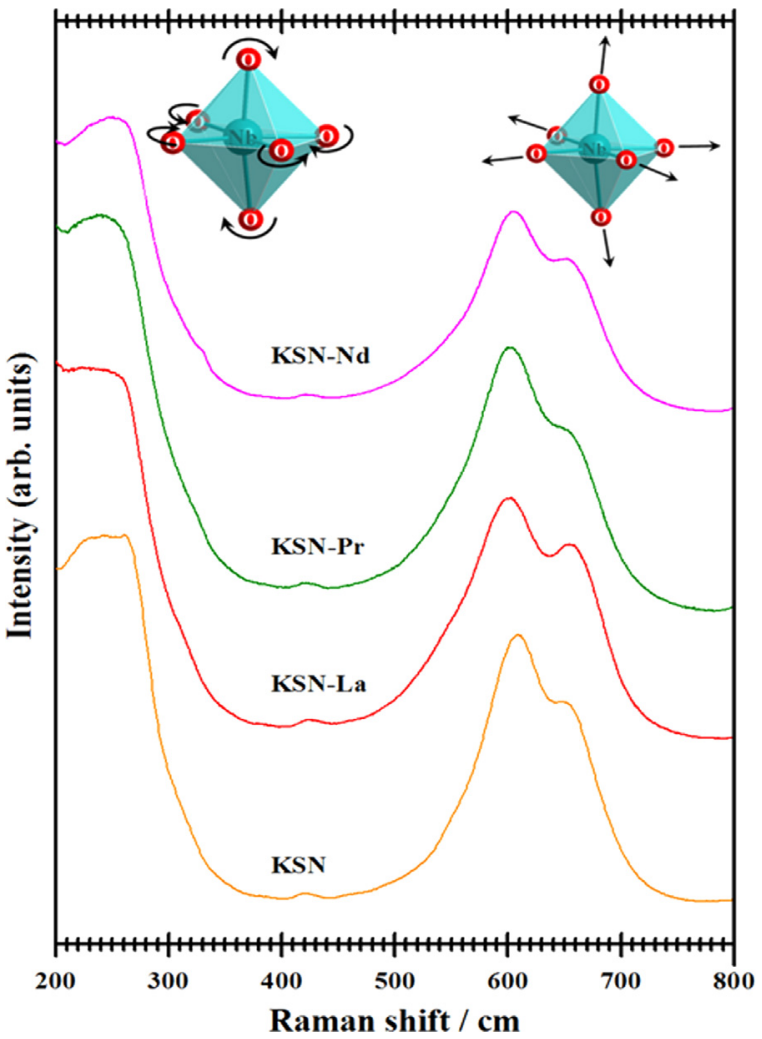

Fig. 3. Raman spectra of KSN and KSN-Ln ( $L n=\mathrm{La}, \mathrm{Pr}$, and Nd).

and are responsible for the appearing of a large number of intermediary energy levels between the valence and conduction bands [21]. These states are classified basically in deep and shallow levels [22]. At room temperature, the deep levels contribute to green, yellow, orange and red PL emissions, while the violet and blue emissions are ascribed to shallow levels [23].

Fig. 4 shows the PL and UV-vis spectra of KSN-Ln samples. The band gap energies $\left(E_{g}\right)$ were calculated according to the Kubelka-Munk equation, extrapolating the linear portion of the UV-vis curves. Although $E_{g}$ values of a given solid material could vary depending on the extrapolation method and optical electronic transition, the use of diffuse reflectance spectroscopy is highly justified [24]. Usually, band gap energies are reported with one or two decimal places, which introduces some uncertainties in the published results. For instance, Miseki and Kudo [25] estimated band gaps between 3.1 and $3.4 \mathrm{eV}$ for doped KSN. Despite the fact that the $E_{g}$ values shown in Fig. 4 can be within the experimental error (shown in Suplementary Data), the distinct values from one sample to another indicates the presence of intermediary energy levels within the forbidden band gap.

Three broad bands centered at approximately $450 \mathrm{~nm}$ (blue), $616 \mathrm{~nm}$ (orange) and $773 \mathrm{~nm}$ (near-infrared) were identified in PL spectra of KSN and KSN-La. However, the intensity of the band located at $616 \mathrm{~nm}$ in the spectrum of KSN-La was higher than in the spectrum of pure KSN, which suggests the presence of lanthanum atoms resulting in deep levels in the band structure. On the other hand, PL spectra of KSN-Pr and 

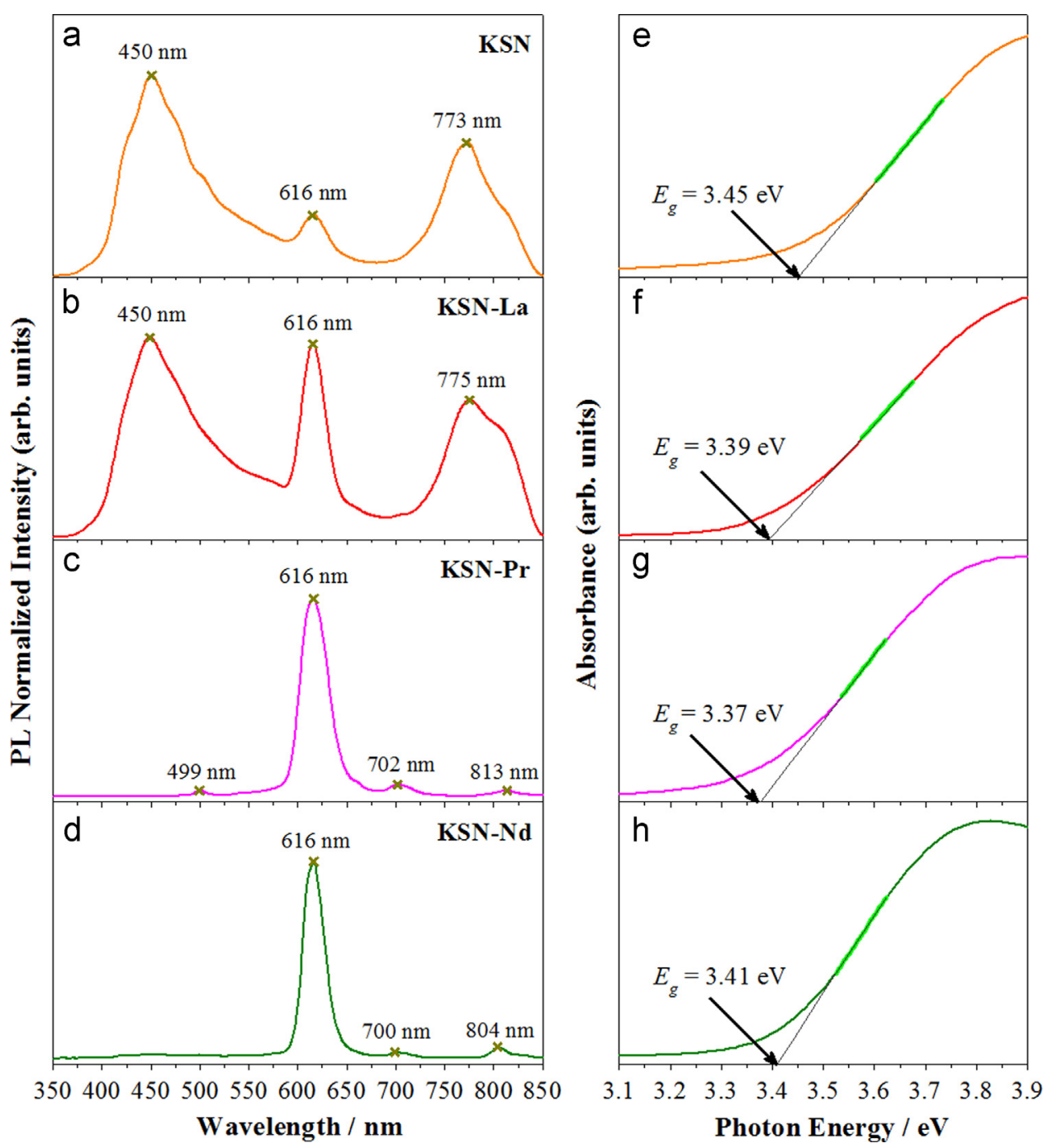

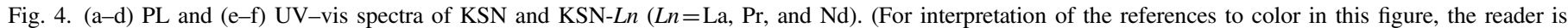
referred to the web version of this article.)

KSN-Nd showed an intense band at $616 \mathrm{~nm}$ and new emission bands of low intensity that are directly related to particular electronic transitions of praseodymium and neodymium. For the KSN-Pr, there are four PL bands related to $4 \mathrm{f} 5 \mathrm{~d}-4 \mathrm{f}^{2}$ transitions of praseodymium $\left(\mathrm{Pr}^{3+}\right)$. In this case, they are centered at around $499 \mathrm{~nm}$ (green), $616 \mathrm{~nm}$ (orange), $702 \mathrm{~nm}$ (red), and $813 \mathrm{~nm}$ (near-infrared), as a result of ${ }^{3} \mathrm{P}_{0} \rightarrow{ }^{3} \mathrm{H}_{4}$, ${ }^{3} \mathrm{P}_{0} \rightarrow{ }^{3} \mathrm{H}_{6},{ }^{3} \mathrm{P}_{0} \rightarrow{ }^{3} \mathrm{~F}_{3}$, and ${ }^{1} \mathrm{D}_{2} \rightarrow{ }^{2} \mathrm{H}_{6}$ transitions, respectively [26-28]. PL property of neodymium $\left(\mathrm{Nd}^{3+}\right)$ is ascribed to $4 f^{2} 5 d^{1}-4 f^{3}$ transitions from excited to ground state. Consequently, its spectrum exhibits typical emissions of $\mathrm{Nd}^{3+}$ located at $616 \mathrm{~nm}$ (orange), $700 \mathrm{~nm}$ (red) and $804 \mathrm{~nm}$ (nearinfrared) from ${ }^{4} \mathrm{I}_{9 / 2} \rightarrow{ }^{4} \mathrm{G}_{5 / 2},{ }^{4} \mathrm{I}_{9 / 2} \rightarrow{ }^{4} \mathrm{~F}_{9 / 2}$, and ${ }^{4} \mathrm{I}_{9 / 2} \rightarrow{ }^{2} \mathrm{H}_{9 / 2}$ transitions, respectively [29-31]. Besides their specific electronic transitions, the Janh-Teller (JT) effect is also responsible for some modifications in PL spectra of doped samples [32]. In this case, when the TTB-type structure is doped with lanthanides, the crystal field around the $L n$ atoms is significantly perturbed, resulting in distortions in the lattice. This supposition is in good agreement with the results shown in Table 1 and with the Raman spectra (Fig. 3). It is important to emphasize that the UV-vis absorption spectra confirms the incorporation of $\mathrm{Pr}$ and $\mathrm{Nd}$ in the KSN host lattice because of their respective band edges (Figures S5 and S6 in Supplementary Data). The wavelengths of these bands are nearly the same of the peaks found in the excitation spectra of other materials [29,33,34].

It is clear that the replacement of sites commonly occupied by $\mathrm{Sr}$ for those lanthanide atoms as well as the existence of uncountable structural defects in the crystalline lattice are sufficiently important to affect the lattice parameters and the electronic band structure. For instance, the distortions introduced in $\left[\mathrm{NbO}_{6}\right]$ clusters of the TTB-type structure by the doping lanthanide elements modified the intensity of PL bands due the creation of significant changes in the degree of structural order-disorder. These changes resulted in different energies of band gap and evident influence on the PL spectra not related to intrinsic atomic properties of the doping element, but entirely dependent on the defects or distortions created in the crystalline lattice. This kind of atom substitution offers the 
possibility to tune the PL characteristics of oxides simply doping the host structure with atoms specially selected to modify the bond lengths or angles, independently of their electronic transitions.

\section{Conclusions}

XRD patterns and Rietveld refinements revealed all KSN- $\mathrm{Ln}$ samples crystallized in the TTB-type structure without the presence of secondary phases, confirming the suitability of the Pechini route to obtain this class of complex materials. The structural analysis showed the existence of structural distortions in $\mathrm{O}-\mathrm{Nb}-\mathrm{O}$ and $\mathrm{Nb}-\mathrm{O}-\mathrm{Nb}$ bonds related to the presence of different rare earth elements in the composition ( $\mathrm{La}, \mathrm{Pr}$, and $\mathrm{Nd}$ ). The slight shift of the band at $600 \mathrm{~cm}^{-1}$ in Raman spectra to lower wavelength was associated to modifications in $\mathrm{O}-\mathrm{Nb}-$ $\mathrm{O}$ bond distances introduced by the presence of lanthanides. The different $E_{g}$ values verified in all samples suggested the existence of several intermediary energy levels within the forbidden band. These levels originated from structural defects caused by the replacement of $\mathrm{Sr}$ atoms for $\mathrm{Ln}$. The doping lanthanide influenced the PL profiles of KSN, while the KSN$\mathrm{Pr}$ and KSN-Nd samples exhibited the predominance of their typical charge transfer transitions of $\mathrm{Pr}^{3+}$ and $\mathrm{Nd}^{3+}$ in relation to the spectra of KSN host.

\section{Acknowledgment}

The authors are grateful to the CAPES, FAPESP and CNPq for the financial support. Grants 2012/07067-0 and 2013/ 07296-2, São Paulo Research Fundation (FAPESP).

\section{Appendix A. Supplementary material}

Supplementary data associated with this article can be found in the online version at http://dx.doi.org/10.1016/j.ceramint. 2015.11.130.

\section{References}

[1] E.R. Camargo, F.L. Souza, E.R. Leite, M. Kakihana, Structural and electrical characterization of dense lead zirconate titanate ceramics synthesized by the oxidant-peroxo wet-chemical route, J. Appl. Phys. 96 (2004) 2169-2172.

[2] L. Liu, F. Gao, G. Hu, J. Liu, Effect of excess $\mathrm{Nb}_{2} \mathrm{O}_{5}$ on the growth behavior of $\mathrm{KSr}_{2} \mathrm{Nb}_{5} \mathrm{O}_{15}$ particles by molten salt synthesis, Powder Technol. 235 (2013) 806-813.

[3] S. Lanfredi, M.A.L. Nobre, A.R.F. Lima, Análise cristalográfica da solução sólida com estrutura tipo tungstênio bronze de niobato de potássio e estrôncio dopado com ferro, Quim. Nova 33 (2010) 1071-1076.

[4] B.A. Scott, E.A. Giess, D.F. O'kane, G. Burns, Phase equilibria in the $\mathrm{KNbO}_{3}-\mathrm{SrNb}_{2} \mathrm{O}_{6}$ and $\mathrm{KNbO}_{3}-\mathrm{BaNb}_{2} \mathrm{O}_{6}$ systems, J. Am. Ceram. Soc. 53 (1970) 106-109.

[5] P.B. Jamieson, S.C. Abrahams, J.L. Bernstein, Ferroelectric tungsten bronze type crystal structures. I. barium strontium niobate $\mathrm{Ba}_{0.27} \mathrm{Sr}_{0.75} \mathrm{Nb}_{2} \mathrm{O}_{5.78}$, J. Chem. Phys. 48 (1968) 5048-5057.
[6] P.B. Jamieson, S.C. Abrahams, J.L. Bernstein, Ferroelectric tungsten bronze type crystal structures. II. barium sodium niobate $\mathrm{Ba}_{(4+x)}$ $\mathrm{Na}_{(2-2 x)} \mathrm{Nb}_{10} \mathrm{O}_{30}$, J. Chem. Phys. 50 (1969) 4352-4363.

[7] S. Alkoy, C. Duran, A.D. Hall, Electrical properties of textured potassium strontium niobate $\left(\mathrm{KSr}_{2} \mathrm{Nb}_{5} \mathrm{O}_{15}\right)$ ceramics fabricated by reactive templated grain growth, J. Am. Ceram. Soc. 91 (2008) 1597-1602.

[8] S. Lanfredi, D.H.M. Gênova, I.A.O. Brito, A.R.F. Lima, M.A.L. Nobre, Structural characterization and Curie temperature determination of a sodium strontium niobate ferroelectric nanostructured powder, J. Solid State Chem. 184 (2011) 990-1000.

[9] G. Zhu, Z. Ci, C. Ma, Y. Shi, Y. Wang, A novel red emitting phosphor of $\mathrm{Eu}^{3+}$ doped TTB-type niobate $\mathrm{NaSr}_{2} \mathrm{Nb}_{5} \mathrm{O}_{15}$ for white LEDs, Mater. Res. Bull. 48 (2013) 1995-1998.

[10] X. Ding, G. Zhu, Y. Shi, Y. Wang, Synthesis and luminescent properties of a white light phosphor $\mathrm{KBa}_{2} \mathrm{Nb}_{5} \mathrm{O}_{15}: \mathrm{Na}^{+}$, $\mathrm{Dy}^{3+}$ for light-emittingdevices, Mater. Res. Bull. 48 (2013) 3648-3650.

[11] M.P. Pechini, Method of preparing lead and alkaline earth titanates and niobates and coating method using the same to form a capacitor, U.S. Patent 3,330,697, (1967).

[12] J.M. Calderon-Moreno, E.R. Camargo, Electron microscopy studies on the formation and evolution of sodium niobate nanoparticles from a polymeric precursor, Catal. Today 78 (2003) 539-542.

[13] M. Kakihana, Invited review "sol-gel" preparation of high temperature superconducting oxides, J. Sol-Gel Sci. Technol. 6 (1996) 7-55.

[14] A.C. Larson, R.B. Von Dreele, General Structure Analysis System (GSAS), Los Alamos National Laboratory, 1994, p. 86-748 Report LAUR.

[15] H.E.A. Belghiti, A. Simon, P. Gravereau, A. Villesuzanne, M. Elaatmani, J. Ravez, Ferroelectric and crystallographic properties of the $\mathrm{Sr}_{2-x} \mathrm{~K}_{1+x} \mathrm{Nb}_{5} \mathrm{O}_{15-x} \mathrm{~F}_{x}$ solid solution, Solid State Sci. 4 (2002) 933-940.

[16] H. Putz, K. Brandenburg GbR, Diamond, version 2010.3.2, crystal and molecular structure visualization, see: 〈http://www.crystalimpact.com/ diamond $>$.

[17] J.M. Jehng, I.E. Wachs, Structural chemistry and Raman spectra of niobium oxides, Chem. Mater. 3 (1991) 100-107.

[18] E. Amzallag, T.S. Chang, R.H. Pantell, R.S. Feigelson, Raman scattering by $\mathrm{Sr}_{x} \mathrm{Ba}_{1-x} \mathrm{Nb}_{2} \mathrm{O}_{6}$, J. Appl. Phys. 42 (1971) 3254-3256.

[19] K.G. Bartlett, L.S. Wall, Temperature study of the polarized Raman spectra of strontium barium niobate, J. Appl. Phys. 44 (1973) 5192-5193.

[20] P.R. Lucena, E.R. Leite, F.M. Pontes, E. Longo, P.S. Pizani, J.A. Varela, Photoluminescence: a probe for short, medium and long-range selforganization order in $\mathrm{ZrTiO}_{4}$ oxide, J. Solid State Chem. 179 (2006) 3997-4002.

[21] V.M. Longo, A.T. de Figueiredo, S. de Lázaro, M.F. Gurgel, M.G. S. Costa, C.O. Paiva-Santos, J.A. Varela, E. Longo, V.R. Mastelaro, F. S. de Vicente, A.C. Hernandes, R.W.A. Franco, Structural conditions that leads to photoluminescence emission in $\mathrm{SrTiO}_{3}$ : an experimental and theoretical approach, J. Appl. Phys. 104 (2008) 023515.

[22] J.L. Lyons, A. Janotti, C.G. Van de Walle, Shallow versus deep nature of Mg acceptors in nitride semiconductors, Phys. Rev. Lett. 108 (2012) 156403.

[23] S.K. Rout, L.S. Cavalcante, J.C. Sczancoski, T. Badapanda, S. Panigrahi, M. Siu, Li, E. Longo, Photoluminescence property of $\mathrm{Ba}\left(\mathrm{Zr}_{0.25} \mathrm{Ti}_{0.75}\right) \mathrm{O}_{3}$ powders prepared by solid state reaction and polymeric precursor method, Physica B 404 (2009) 3341-3347.

[24] R. Lopez, R. Gomez, Band-gap energy estimation from diffuse reflectance measurements on sol-gel and commercial $\mathrm{TiO}_{2}$ : a comparative study, J. Sol-Gel Sci. Technol. 61 (2012) 1-7.

[25] Y. Miseki, A. Kudo, Water splitting over new niobate photocatalysts with tungsten-bronze-type structure and effect of transistion metal-doping, ChemSusChem 4 (2011) 245-251.

[26] A. Lazarowska, S. Mahlik, M. Krosnicki, M. Grinberg, M. Malinowski, Pressure-induced phase transition in $\mathrm{LiLuF}_{4}: \mathrm{Pr}^{3+}$ investigated by an optical technique, J. Phys.: Condens. Matter 24 (2012) 115502.

[27] F. Ramos-Brito, H. Murrieta, J. Hernández, E. Camarillo, M. GarcíaHipólito, R. Martínez-Martínez, O. Álvarez-Fragoso, C. Falcony, Photoluminescent spectroscopy measurements in nanocrystalline 
praseodymium doped zirconia powders, J. Phys. D: Appl. Phys. 39 (2006) 2079-2083.

[28] Y. Zhang, Z. Sun, Optically pumped infrared stimulated radiation in $\mathrm{Pr}^{3+}: \mathrm{Y}_{2} \mathrm{SiO}_{5}$, Chin. Opt. Lett. 1 (2003) 168-170.

[29] M. Qureshi, H.Y. Chen, C.H. Lu, Synthesis and photoluminescent properties of neodymium-ion doped perovskite oxides, Solid State Commun. 142 (2007) 85-88.

[30] V.S. Marques, L.S. Cavalcante, J.C. Sczancoski, E.C. Paris, J.M. C. Teixeira, J.A. Varela, F.S. de Vicente, M.R. Joya, P.S. Pizani, M. Siu, Li, M.R.M.C. Santos, E. Longo, Synthesis of $(\mathrm{Ca}, \mathrm{Nd}) \mathrm{TiO}_{3}$ powders by complex polymerization, Rietveld refinement and optical properties, Spectrochim. Acta Part A 74 (2009) 1050-1059.
[31] K. Lemański, A. Gagor, M. Kurnatowska, R. Pązik, P.J. Dereń, Spectroscopic properties of $\mathrm{Nd}^{3+}$ ions in nano-perovskite $\mathrm{CaTiO}_{3}$, J. Solid State Chem. 184 (2011) 2713-2718.

[32] M.N. Sanz-Ortiza, F. Rodríguez, Photoluminescence properties of JahnTeller transition-metal ions, J. Chem. Phys. 131 (2009) 124512.

[32] P. Boutinaud, R. Mahiou, E. Cavalli, M. Bettinelli, Excited state dynamics of $\mathrm{Pr}^{3+}$ in $\mathrm{YVO}_{4}$ crystals, J. Appl. Phys. 96 (2004) 4923-4929.

[33] A. Méndez-Blas, M. Rico, V. Volkov, C. Cascales, C. Zaldo, C. Coya, A. Kling, L.C. Alves, Optical spectroscopy of $\mathrm{Pr}^{3+}$ in $\mathrm{M}^{+} \mathrm{Bi}\left(\mathrm{XO}_{4}\right)_{2}$, $\mathrm{M}^{+}=\mathrm{Li}$ or $\mathrm{Na}$ and $\mathrm{X}=\mathrm{W}$ or Mo, locally disordered single crystals, $\mathrm{J}$. Phys.: Condens. Matter 16 (2004) 2139-2160.

[34] F. Ramos-Lara, A. Lira, C.,M.O. Ramírez, M. Flores, R. Arroyo, U. Caldiño, Optical spectroscopy of $\mathrm{Nd}^{3+}$ ions in poly (acrylic acid), J. Phys.: Condens. Matter 18 (2006) 7951-7959. 